\title{
In Vivo Stable Transduction of Humanized Liver Tissue in Chimeric Mice via High-Capacity Adenovirus-Lentivirus Hybrid Vector
}

\author{
Shuji Kubo,,2 Miho Kataoka, ${ }^{3}$ Chise Tateno, ${ }^{3}$ Katsutoshi Yoshizato,, ${ }^{3,4}$ Yoshiko Kawasaki, ${ }^{2}$ Takahiro Kimura, \\ Emmanuelle Faure-Kumar, Donna J. Palmer, ${ }^{1}$ Philip Ng, ${ }^{5}$ Haruki Okamura, ${ }^{2}$ and Noriyuki Kasahara ${ }^{1}$
}

\begin{abstract}
We developed hybrid vectors employing high-capacity adenovirus as a first-stage carrier encoding all the components required for in situ production of a second-stage lentivirus, thereby achieving stable transgene expression in secondary target cells. Such vectors have never previously been tested in normal tissues, because of the scarcity of suitable in vivo systems permissive for second-stage lentivirus assembly. Here we employed a novel murine model in which endogenous liver tissue is extensively reconstituted with engrafted human hepatocytes, and successfully achieved stable transduction by the second-stage lentivirus produced in situ from first-stage adenovirus. This represents the first demonstration of the functionality of adenoviral-lentiviral hybrid vectors in a normal parenchymal organ in vivo.
\end{abstract}

\section{Introduction}

A DENOVIRAL VEctors (AdVs) have been successfully used in vivo to transduce various postmitotic tissues, but generally only transient gene expression can be achieved because of cytotoxic T-lymphocyte-mediated immune responses against viral genes retained in conventional AdVs, and their extremely low frequency of chromosomal integration (Harui et al., 1999; Wivel et al., 1999). More persistent expression can be maintained by high-capacity, helperdependent AdVs (HDAdVs) from which all of the viral coding sequences have been removed (Parks et al., 1996; Schiedner et al., 1998; Kochanek, 1999; Kim et al., 2001; Oka et al., 2001), but its duration is still limited because of progressive dilution of the extrachromosomal HDAdV vector DNA as transduced cells divide. Treatment of hereditary diseases may require more stable, long-term transgene expression, which can be achieved only through permanent integration or ongoing episomal replication of vector DNA.

To overcome this limitation, various hybrid vector systems have been developed, which employ AdV as a first-stage delivery vehicle to efficiently enter target cells, but then utilize the machinery of integrating viruses or mobile genetic elements to achieve permanent chromosomal integration (Feng et al., 1997; Caplen et al., 1999; Lieber et al., 1999; Recchia et al., 1999; Tan et al., 1999; Leblois et al., 2000; Soifer et al., 2001; Soifer et al., 2002; Yant et al., 2002; Kubo and Mitani, 2003; Dorigo et al., 2004; Picard-Maureau et al., 2004). Efficient two-stage transduction in vitro and stable long-term transgene expression have previously been demonstrated with AdV-transposon (Soifer et al., 2001; Yant et al., 2002), AdV-adeno-associated virus (Lieber et al., 1999; Recchia et al., 1999), AdV-retrovirus (Feng et al., 1997; Caplen et al., 1999; Soifer et al., 2002), AdV-foamy virus (Picard-Maureau et al., 2004), and AdV-lentivirus (Kubo and Mitani, 2003) vectors. In particular, Kubo and Mitani (2003) have demonstrated the ability of an AdV-lentivirus hybrid vector to efficiently enter a variety of cell types via the first-stage HDAdV and subsequently mediate in situ production of a human immunodeficiency virus (HIV)-derived second-stage lentiviral vector (LV), which then stably delivers a marker gene to neighboring cells. However, this hybrid vector generated secondstage LV pseudotyped with the vesicular stomatitis virus $G$ glycoprotein (VSV-G), a highly fusogenic and toxic envelope

\footnotetext{
${ }^{1}$ Division of Digestive Diseases, Department of Medicine, University of California at Los Angeles, Los Angeles, CA 90095.

${ }^{2}$ Laboratory of Host Defenses, Institute for Advanced Medical Sciences, Hyogo College of Medicine, Nishinomiya, Hyogo 663-8501, Japan.

${ }^{3}$ Yoshizato Project, CLUSTER, Hiroshima Prefectural Institute of Industrial Science and Technology, Higashi-Hiroshima, Hiroshima 7390046, Japan.

${ }^{4}$ Developmental Biology Laboratory and Hiroshima University 21st Century COE Program for Advanced Radiation Casualty Medicine, Department of Biological Science, Graduate School of Science, Higashi-Hiroshima, Hiroshima 739-8526, Japan.

${ }^{5}$ Center for Cell \& Gene Therapy, Baylor College of Medicine, Houston, TX 77030.
} 
protein (Ory et al., 1996), which may result in unwanted cytotoxic effects in the primary target cells during LV production. Further, the ability of AdV-lentivirus hybrid vectors to stably transduce normal quiescent tissues in vivo has never previously been tested.

We have now developed an improved high-capacity AdVlentivirus hybrid vector system, designated HL, and examined the ability of this new hybrid system to mediate efficient and stable gene transfer in vitro and in vivo. The first-stage HDAdV of the HL hybrid system directs the production of a minimal second-stage LV that retains less than $800 \mathrm{bp}$ of HIV sequence (Chen et al., 2002) and is pseudotyped with the murine leukemia virus (MLV) 4070A amphotropic envelope, which is much less cytotoxic than VSV-G. However, to test the transduction efficiency of the new HL hybrid vector system, target cells that can support in situ production of the HIV-derived second-stage LV are required. For in vitro experiments, human cell lines permissive for HIV replication can be employed. However, the requirement for human target cells presents a challenge to testing the functionality of the HL hybrid vector system in vivo, particularly with respect to its ability to stably transduce normal organs and tissues.

As nearly $90 \%$ of the input dose of $\mathrm{AdV}$ introduced in vivo accumulates in the liver upon intravenous injection (KassEisler et al., 1994; Huard et al., 1995; Kubo et al., 1997), and nearly $100 \%$ transduction of hepatocytes can be achieved at higher doses (Li et al., 1993), the liver is an attractive target for in vivo testing of the HL system. However, multiple blocks to HIV replication have been reported in rodent cells, including cellular entry, reduced abundance of unspliced HIV-RNA and gag proteins, and defects in infectious particle assembly (Hofmann et al., 1999; Bieniasz and Cullen, 2000; Mariani et al., 2000). Therefore, to test the HL hybrid vector in vivo, we sought a humanized liver model that is permissive for HIV particle assembly.

Successful reconstitution of human liver tissue has recently been achieved in immunodeficient mice (Dandri et al., 2001; Mercer et al., 2001). Dandri et al. (2001) reported that crossbreeding of recombinant activation gene-2-deleted mice with transgenic mice expressing the hepatotoxic urokinase-type plasminogen activator (uPA) results in immunodeficient progeny which undergo progressive liver degeneration. These progeny were successfully transplanted with human hepatocytes, resulting in chimeric liver tissue with a replacement index of up to $15 \%$, rendering these mice permissive for HBV infection (Dandri et al., 2001). Similarly, Mercer et al. (2001) demonstrated that uPA/SCID mice bearing chimeric humanized livers with replacement index values of $50 \%$ could support HCV replication (Dandri et al., 2001). More extensive repopulation has been difficult to achieve, likely because engrafted human hepatocytes produce complement factors, which appear to exert lethal effects in mice with higher replacement values. However, Tateno et al. (2004) and Yoshizato and colleagues (2004) have recently demonstrated that administration of a C5/C3 convertase inhibitor successfully rescued uPA/SCID mice whose chimeric livers proved to be almost completely repopulated with human hepatocytes exhibiting normal cytoarchitecture. The transduction efficiency of oncoretroviral vectors has previously been tested in this humanized liver model, and consistent with their inability to enter quiescent postmitotic cells, was found to be in the order of $5 \%$ (Emoto et al., 2005). We have now utilized this unique chimeric liver model to test the ability of the HL hybrid system to mediate efficient entry by the first-stage HDAdV, in situ production of the second-stage LV, and stable transduction in fully humanized livers in vivo. To our knowledge, this represents the first report of in vivo testing of an AdV-lentivirus hybrid vector system in a normal parenchymal organ.

\section{Materials and Methods}

\section{Cells}

Cell lines including 293 (Graham et al., 1977) (Microbix, Toronto, Canada), 293T (DuBridge et al., 1987), and the Gli36 human glioma (Sena-Esteves et al., 2000) were cultured in Dulbecco's modified Eagle's medium supplemented with 10\% fetal calf serum (FCS; Omega, Tarzana, CA). Hep3B human hepatocellular carcinoma cells were cultured in Eagle's minimum essential medium supplemented with $10 \%$ FCS, $1 \mathrm{mM}$ sodium pyruvate, and nonessential amino acids. Primary human hepatocytes and their specific medium were purchased from Cambrex (Baltimore, MD; CC-2591).

\section{HL first-stage HDAdV construction and production}

The phosphoglycerokinase promoter-driven green fluorescence protein (GFP) marker gene cassette, cytomegalovirus promoter (CMV)-driven $\mathrm{gag} / \mathrm{pol} / \mathrm{rev}$ lentiviral packaging cassette, simian virus 40 early promoter-driven MLV 4070A amphotropic envelope cassette, and minimal LV construct (Robbins et al., 1998; Chen et al., 2002) were sequentially cloned into the HDAdV plasmid pSTK120, which contains the human Ad5 inverted terminal repeat sequences and packaging signal, resulting in the construction of the complete HL vector plasmid, pHL. Additional details regarding the $\mathrm{pHL}$ construct, and the HIV-based minimal LV contained therein, are provided upon request.

The HL vector and control HDAdV cmv-GFP (Ad GFP) were prepared using the FLPe/FRT helper virus system (Umana et al., 2001). The vectors were titrated on 293 cells for GFP expression, using a FACScalibur flow cytometer (Becton Dickinson, San Jose, CA), on day 2 post-infection, defined as transducing units per $\mathrm{ml}(\mathrm{TU} / \mathrm{ml})$. Another control HDAdV, HDA28E4LacZ, was prepared as previously described (Palmer and $\mathrm{Ng}$, 2003). Helper virus contamination levels were determined by Southern blot, as previously described (Kubo and Mitani, 2003).

\section{Second-stage $L V$ production after infection with HL first-stage HDAdV}

To confirm production of LV in cells (Gli36, HeLa, Hep3B, HepG2 and human primary hepatocytes) infected by the HL vector, $4 \times 10^{5}$ cells of each were infected with various amounts of HL vector. The amount of vector used for each infection was based on the titer determined using each cell line. At $4 \mathrm{hr}$ postinfection, the infected cells were washed three times with phosphate-buffered saline (PBS), and incubated in growth medium. At $48 \mathrm{hr}$ postinfection, the virus-containing medium was harvested, centrifuged, filtered through a $0.45-\mu \mathrm{m}$ pore filter, and used for titration on 293 cells by $\mathrm{X}$ galactosidase (gal) staining to detect $\beta$ gal expression. In preliminary experiments, the level of residual adenovirus carried over in the filtered supernatant medium after infection of primary cells at a multiplicity of infection (MOI) of 10, as 
measured by flow cytometry for GFP expression in secondary cells, was less than $1 \%$.

To inhibit lentiviral infection, 293 cells were infected with the viral supernatant in the presence or absence of $5 \mu \mathrm{M}$ zidovudine (AZT; Sigma, St. Louis, MO).

To investigate the kinetics of $\mathrm{LV}$ vector production after HL vector infection, $4 \times 10^{5} \mathrm{Hep} 3 \mathrm{~B}$ cells were infected with $\mathrm{HL}$ at various MOIs in six-well plates. The medium was collected at different time points and titrated on 293 cells, as described earlier.

\section{Long-term culture experiments}

Hep3B cells $\left(2 \times 10^{5}\right)$ were infected with the HL vector, at an MOI of 10, and incubated in the presence of AZT on a 10-cm dish. The cells were split at a ratio of 1:20 once a week, and expression of GFP was examined by flow cytometry. At each passage, DNA was extracted from a portion of the cells and analyzed for proviral integration by Southern hybridization. A part of the HL-infected cells were also plated on Lab-Tek chamber slides (Thermo Fisher Scientific, Rochester, NY). The next day, the cells were fixed for 10 min with $4 \%$ paraformaldehyde, washed with PBS, and incubated with $50 \mathrm{mM} \mathrm{NH}_{4} \mathrm{Cl}$ in PBS for $5 \mathrm{~min}$. The cells were permeabilized in $0.5 \%$ Triton/PBS for $5 \mathrm{~min}$ and then incubated for $30 \mathrm{~min}$ in $1 \%$ bovine serum albumin/PBS for blocking. The cells were incubated for $1 \mathrm{hr}$ with a 1:1000 dilution of mouse antiGFP monoclonal (Chemicon, Temecula, CA). Immunoreactivity for GFP was visualized with a 1:5000 dilution of goat anti-mouse immunoglobulin G (IgG) $(\mathrm{H}+\mathrm{L})$ Alexa Fluor 488. The cells were then incubated with a 1:1000 dilution of rabbit anti- $\beta$ gal polyclonal (ab616; Abcam, Cambridge, MA). Immunoreactivities for $\beta$ gal were visualized with a 1:5000 dilution of goat anti-rabbit $\operatorname{IgG}(\mathrm{H}+\mathrm{L})$ Alexa Fluor 594 (Molecular Probes, Eugene, OR).

\section{Animals}

Chimeric mice with human liver were generated as previously described (Tateno et al., 2004). Briefly, uPA/SCID mice were generated by crossing uPA mice [B6SJLTgN(Alb1Plau)144Bri; The Jackson Laboratory, Bar Harbor, ME] with SCID mice (Fox Chase SCID C.B-17/Icr-scid Jcl; Clea Japan, Tokyo, Japan). The $\mathrm{uPA}^{+/+} \mathrm{SCID}^{+/+}$mice were screened by polymerase chain reaction (PCR) and injected with 5.0-7.5 $\times 10^{5}$ viable human hepatocytes (IVT079; In Vitro Technologies Inc., Baltimore, MD) through a small left-flank incision into the inferior splenic pole at 20-30 days after birth. The mice were injected intraperitoneally with $200 \mu \mathrm{l}$ of $1.5 \mathrm{mg} / \mathrm{ml}$ Futhan (nafamostat mesilate, 6-amidino-2-naphthyl $p$-guanidinobenzoate dimethanesulfonate; gift from Torii Pharmaceutical, Tokyo, Japan) to enhance repopulation of the liver with human hepatocytes. The replacement index was estimated by serum level of human albumin as previously described (Tateno et al., 2004). Generally, $>5 \mathrm{mg} / \mathrm{ml}$ human albumin in the blood indicates high replacement index values of $>70 \%$, and mice screened in this manner were used for experiments at 6-8 weeks posttransplantation.

After injection with gadolinium ( $10 \mathrm{mg} / \mathrm{kg}$ body weight) to eliminate Kupffer cells (Lieber et al., 1997), either HL vector $\left(2 \times 10^{9} \mathrm{TU} / 200 \mathrm{ml}\right)$ or buffer (PBS) was injected via tail vein, followed by sacrifice at 4 days or 4 weeks postinfection ( $n=4$ per group). A portion of each liver sample was im- mediately digested into cell suspensions and used for flow cytometric analysis. The remaining portion was frozen in liquid nitrogen for isolation of genomic DNA or for frozen tissue sections. Immunofluorescence (IF) and immunohistochemistry (IHC) for GFP were performed on frozen liver sections using standard methods with GFP-specific antibodies (ab290; Abcam): goat anti-rabbit IgG-Alexa Fluor 488 for IF, or Vectastain $\mathrm{ABC}$ kit (Vector Laboratories, Burlingame, $\mathrm{CA}$ ) and diaminobenzidine for IHC. IF for $\beta$ gal was also performed using rabbit anti- $\beta$ gal antibodies (ab616; Abcam) and goat anti-rabbit IgG-Alexa Fluor 594, as earlier. X-gal staining using standard methods was also performed on glutaraldehydefixed liver sections, and the proportion of $\beta$ gal-positive cells was determined by image analysis using the SPOT digital imaging system and NIH ImageJ software (version 1.34). The replacement index of the mouse liver with human hepatocytes was also determined by IHC for human-specific cytokeratin- 8 and -18 (CK8/18) as previously described (Tateno et al., 2004) and is defined as the ratio of area occupied by human hepatocytes to the entire area examined. To assess any potential hepatotoxicity, sera were collected from mice at the time of scheduled sacrifice, that is, at 4 weeks after injection with HL vector or PBS, and serum levels of aspartate amino transferase (AST) were measured by automated colorimetric assay.

\section{Molecular analysis of integrated LVs in the liver}

High-molecular-weight genomic DNA was extracted from livers injected with HL vector or PBS. For detection of the stably integrated form of the second-stage LV after production from the first-stage $\mathrm{HDAdV}$, high-molecular-weight genomic DNA (500 ng) was subjected to nested PCR to amplify lentiviral integration events close to or within Alu repeat sequences in the human genome (Nguyen et al., 2002; Serafini et al., 2004). Briefly, the first PCR (PCR1) was carried out using a sense oligomer specific for the conserved sequences of human Alu (Alu-s; 5'-TCCCAGCTACTCGGGA GGCTGAGG-3') and an antisense oligomer specific for the PBS region of HIV-1 upstream of gag (5NC2-as; 5'-GAGTC CTGCGTCGAGAGAG-3'). All amplifications were done using $100 \mu \mathrm{l}$ of reaction mixture containing $200 \mathrm{ng}$ of genomic DNA, $0.4 \mathrm{mM}$ of each dNTP, $0.8 \mu \mathrm{M}$ of each sense and antisense primer, $5 \%$ dimethyl sulfoxide, and $2 \mathrm{U}$ Taq DNA polymerase. After the first DNA denaturation at $95^{\circ} \mathrm{C}$ for 5 min, 30 amplification cycles were performed consisting of denaturation for $1 \mathrm{~min}$ at $94^{\circ} \mathrm{C}$, annealing for $1 \mathrm{~min}$ at $60^{\circ} \mathrm{C}$, and extension for $3 \mathrm{~min}$ at $72^{\circ} \mathrm{C}$. One aliquot (1:100 dilution) of the first PCR products was subjected to a second PCR (PCR2) amplification using the nested primers, LTR9-s (5'GCCTCAATAAAGCTTGCCTTG-3') and U5PBS-as (spanning the U5LTR/PBS boundary region) (5'-GGCGCCAC TGCTAGAGATTTT- $3^{\prime}$ ), which amplified a fragment of $121 \mathrm{bp}$. The nested PCR conditions were similar to those of the first amplification, except for an annealing temperature of $55^{\circ} \mathrm{C}$ and an extension time of $1 \mathrm{~min}$. Twenty amplification cycles were performed. In control reactions, genomic DNA that had not been subjected to the first round of PCR was also amplified using the second PCR primers to exclude the presence of residual nonintegrated vector DNA. As a loading control, the same DNA samples were subjected to a PCR that amplified a 610 -bp region of human $\beta$-actin $\left(5^{\prime}\right.$-GATCAT GTTTGAGACCTTCA- $3^{\prime}$ and the reverse sequence $5^{\prime}$-ACC 
TTGATCTTCATGGTGC-3'), with the following amplification conditions: $95^{\circ} \mathrm{C}$ for $2 \mathrm{~min}$, then 30 cycles of $95^{\circ} \mathrm{C}$ for $30 \mathrm{sec}, 65^{\circ} \mathrm{C}$ for $30 \mathrm{sec}$, and $72^{\circ} \mathrm{C}$ for $1 \mathrm{~min}$, followed by a final extension at $72^{\circ} \mathrm{C}$ for $5 \mathrm{~min}$. Amplification products were resolved on $1.5 \%$ agarose gel containing ethidium bromide and detected by ultraviolet transillumination.

The copy number of the integrated form of the lentiviral construct in each cell was determined by quantitative realtime PCR (Q-PCR) with $\beta$ gal-specific primers and probe, designed using Primer Express software V. 1.0 (Applied Biosystems, Foster City, CA). Primer and probe sequences spanned a 91-bp region in the $\beta$ gal-coding region, consisting of the following sequences: forward primer, $5^{\prime}$-CTATCCC GACCGCCTTACTG-3'; reverse primer, 5'-GTTTTCGCTCG GGAAGACGTA-3'; probe, 5'-FAM-CAGCGGTCAAAA CAG-TAMRA-3'. Amplification was performed in a reaction volume of $25 \mu \mathrm{l}$ under the following conditions: $300 \mathrm{ng}$ of high-molecular-weight genomic DNA, $1 \times$ Taqman universal PCR master mix (Applied Biosystems), $600 \mathrm{nM}$ forward primer, $900 \mathrm{n} M$ reverse primer, and $100 \mathrm{n} M$ probe. Thermal cycling conditions were $2 \mathrm{~min}$ incubation at $50^{\circ} \mathrm{C}, 10 \mathrm{~min}$ at $95^{\circ} \mathrm{C}$, followed by 40 cycles of successive incubation at $95^{\circ} \mathrm{C}$ for $15 \mathrm{sec}$ and $60^{\circ} \mathrm{C}$ for $1 \mathrm{~min}$. Standard curves were generated using serial dilutions of HL vector plasmid, $\mathrm{pHL}$, from 5 to $50,000,000$ copies in a background of 50,000 equivalents (300 ng) of untransduced genomic DNA from the chimeric mouse liver. Duplicate samples were amplified in an ABI Prism 7700 sequence detector with continuous fluorescence monitoring. Data were collected and analyzed using 7700
Sequence Detection System software v.1.6.3. (Applied Biosystems). The copy number per cell of integrated lentiviral construct was calculated as the average copy number divided by 50,000 cells (equivalent to $300 \mathrm{ng}$ genomic DNA).

\section{Statistical analysis}

The results are presented as mean \pm standard deviation. Statistical significance of differences was calculated using Student's $t$-test, and a $p$-value of $<0.01$ was considered significant.

\section{Results}

\section{Design and production of the HL hybrid vector}

The hybrid vector HL contains a complete set of HIVderived lentiviral packaging components incorporated into an HDAdV (Fig. 1A), including (1) a multiple attenuated packaging construct expressing gag-pol, rev, and the rev response element sequence, (2) an envelope construct expressing amphotropic (i.e., broad mammalian host range) env from MLV strain 4070A, and (3) a minimal HIV-based LV transfer vector encoding a $\beta$ gal marker gene driven by a methylation-resistant MLV promoter (MND promoter) (Chen et al., 2002). As this transfer vector sequence contains a LV packaging signal so that its mRNA will be encapsidated by the coexpressed packaging and envelope components to form LV virions, the $\beta$ gal transgene will not only be expressed in cells directly infected by the HDAdV, but also be transmitted to adjacent cells. The adenoviral backbone
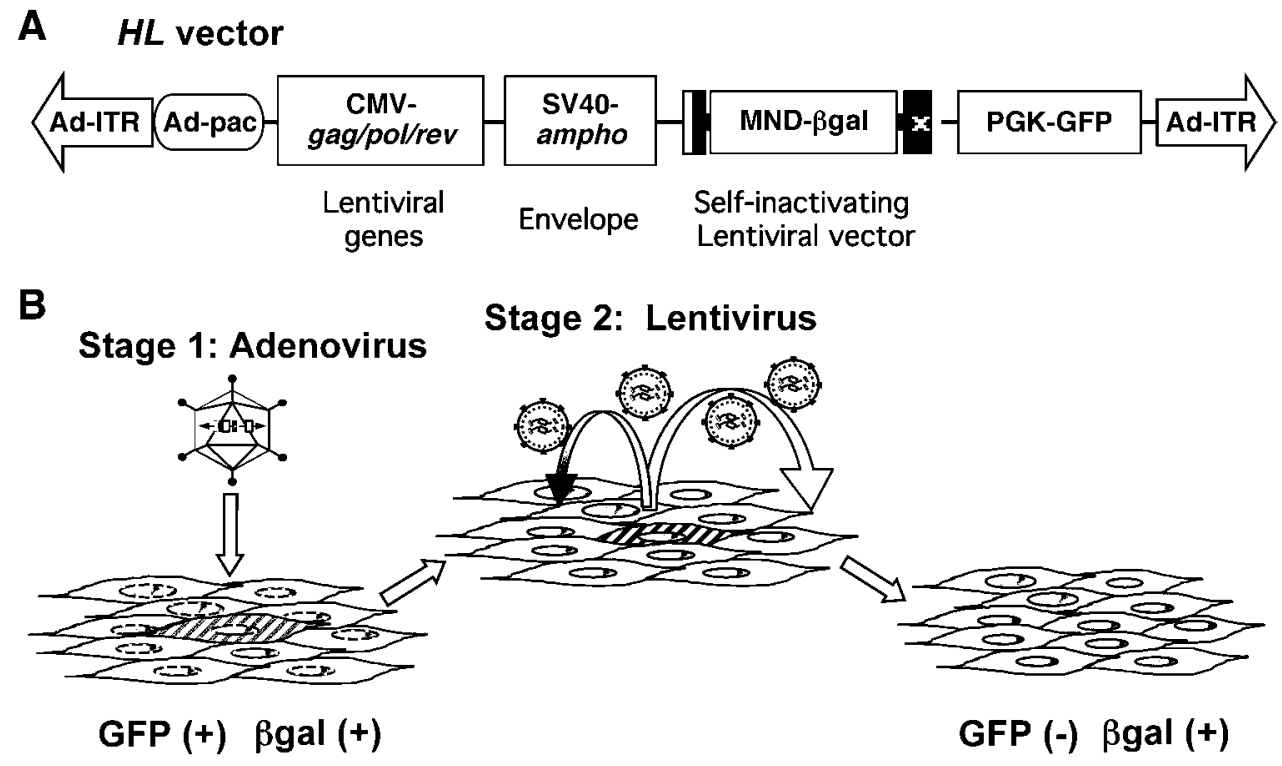

FIG. 1. Outline of the high-capacity adenovirus/lentivirus hybrid vector (HL vector) system. (A) Schematic structure of the HL vector. An HL vector is a helper-dependent adenoviral vector encoding expression cassettes for production of a lentiviral vector (LV) based on human immunodeficiency virus 1 (HIV-1). The HL vector has two inverted terminal repeats (Ad-ITR) and the packaging signal (Ad-pac) of human adenovirus type 5 and encodes four gene expression cassettes: (1) a selfinactivating minimal LV that contains the central polypurine tract, the woodchuck hepatitis virus posttranscriptional regulatory element, and the $\beta$-galactosidase gene ( $\beta$ gal) driven by the methylation-resistant murine leukemia virus LTR promoter (MND) (Robbins et al., 1998; Chen et al., 2002) as a marker; (2) HIV-gag/pol/rev coding sequences driven by cytomegalovirus (CMV) promoter; (3) the amphotropic murine leukemia virus envelope driven by the simian virus 40 early promoter (SV40) for pseudotyping of the lentivirus; and (4) the enhanced green fluorescent protein (GFP) driven by phosphoglycerokinase (PGK) promoter as a marker of the adenoviral backbone. (B) Two-stage transduction with the HL vector. The HL vector infects the initial target cells efficiently as an adenoviral vector and produces an LV in situ. The LV then infects surrounding secondary target cells and integrates into chromosomes for stable gene expression. 
sequence also contains a GFP expression cassette unlinked to the LV components; the GFP marker gene will not be encapsidated into LV particles, thereby allowing specific quantitation of initial transduction by HDAdV itself. Thus, it is possible to distinguish between untransduced cells [GFP $(-), \beta \mathrm{gal}(-)]$, cells transduced by HL first-stage HDAdV only $[\mathrm{GFP}(+), \beta \mathrm{gal}(+)]$, and cells transduced by HL secondstage LV $[\mathrm{GFP}(-), \beta \operatorname{gal}(+)]$ (Fig. 1B).

The first-stage HDAdV was propagated using the FRT/FLPe helper system (Umana et al., 2001). The GFP titers of purified HL vector preparations on 293 cells ranged from $4.1 \times 10^{9}$ to $1.8 \times 10^{10} \mathrm{TU} / \mathrm{ml}$. Vector stocks contained less than $0.1 \%$ helper virus contamination, as determined by Southern hybridization, using a probe for the adenoviral packaging signal (data not shown).

\section{Infection with HL first-stage HDAdV results} in production of functional second-stage $L V$

Following infection by the HL first-stage HDAdV vector at various MOIs, cell-free conditioned media from various human cell lines, including Gli36 (glioma), HeLa (cervical adenocarcinoma), and Hep3B and HepG2 (both hepatocellular carcinoma), were inoculated into fresh 293 cell cultures and tested for their ability to mediate secondary transmission of $\beta$ gal expression. For all primary target cell lines tested, increasing MOI during first-stage HDAdV transduction correlated with increasing $\beta$ gal transmission to secondary target cells (Fig. 2A). Further, $\beta$ gal expression in secondary target cells was markedly suppressed by the reverse transcriptase inhibitor AZT, indicating that the observed transmission was indeed mediated by second-stage LV and was not due to carry-over of the first-stage HDAdV or pseudotransduction by overexpressed $\beta$ gal protein (Fig. 2B). Of the cell lines tested, Gli36 and Hep3B produced the highest titers of LV $\left(1.0 \times 10^{4}\right.$ and $5.1 \times 10^{4} \mathrm{TU} / \mathrm{ml}$, respectively, at MOI =100) (Fig. 2A), which also correlated with high levels of p24 production ( 236 and $316 \mathrm{ng} / \mathrm{ml}$, respectively). Primary human hepatocytes also produced LV at titers of $6.0 \times 10^{1}$, $1.0 \times 10^{3}$, and $1.2 \times 10^{4} \mathrm{TU} / \mathrm{ml}$ upon infection with 1,10 , and $100 \mu \mathrm{l}$ of $\mathrm{HL}$ vector $\left(4.0 \times 10^{8} \mathrm{TU} / \mathrm{ml}\right)$, respectively. Taken together, these findings indicate that the HL hybrid vector is
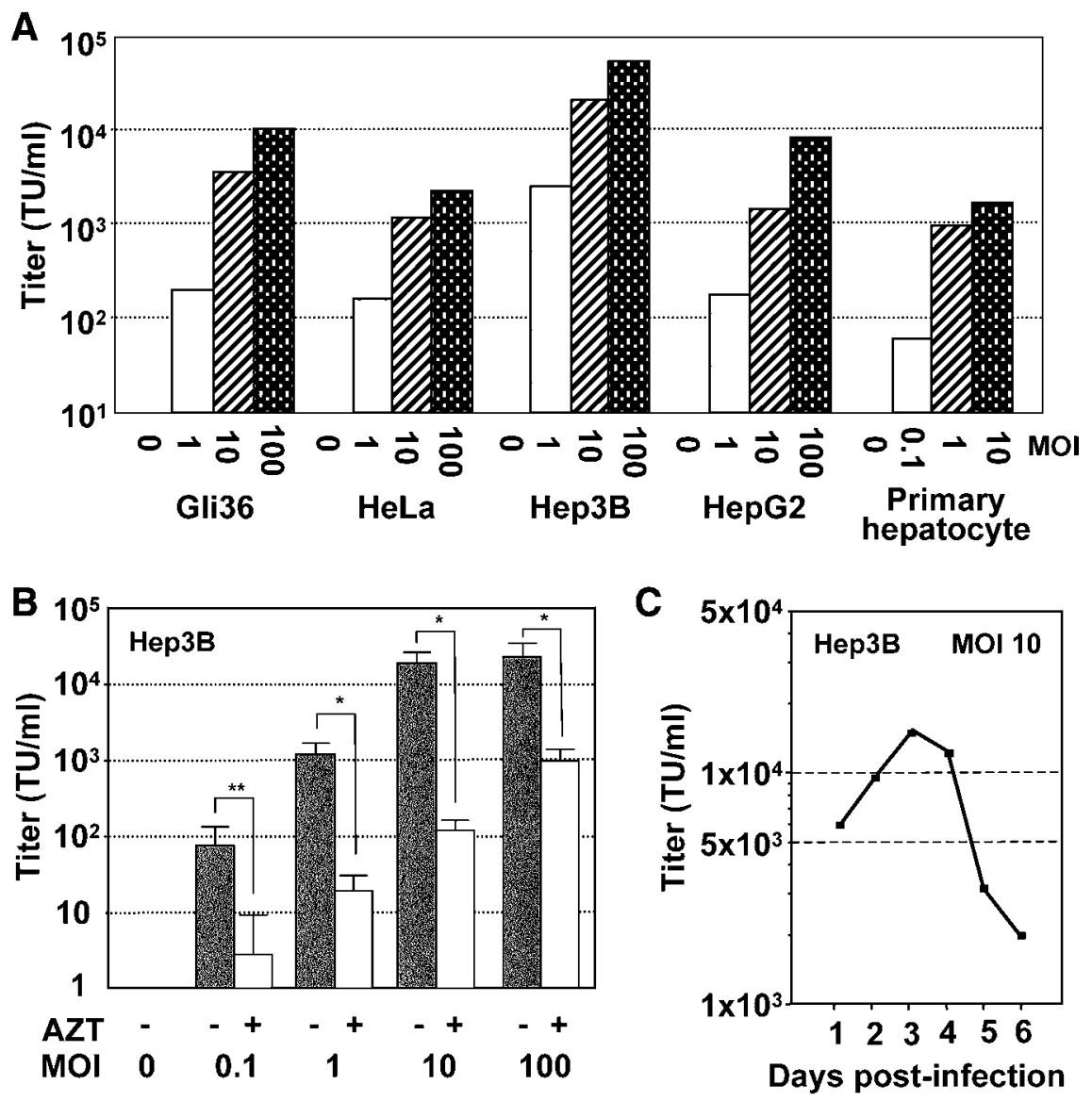

FIG. 2. Production of LV via HL vector system. (A) Production of LV in a variety of cell types after HL infection. Various cell lines indicated in the figure were infected with HL at multiplicity of infections (MOIs) of 1, 10, or 100. After 48 hr, viral supernatant was collected and titrated on 293 cells for $\beta$ gal expression. (B) Production of LV following HL vector infection. Hep3B cells were infected with the HL vector at MOIs of $0.1,1,10$, or 100 . After $48 \mathrm{hr}$, viral supernatant was collected and titrated on 293 cells for $\beta$ gal expression in the presence or absence of zidovudine (AZT, $5 \mu M$ ). Data shown are average titers and standard deviations from the experiment performed in triplicate. Effect of AZT on titers was determined by Student's t-test $\left.{ }^{* *} p<0.05,{ }^{*} p<0.01\right)$. (C) Time course of lentiviral production from Hep3B cells infected with the HL vector. Hep3B cells were infected with HL at an MOI of 10 and monitored for up to 6 days. At different time points indicated in the figure, the medium was replaced, and the viral supernatant was titrated for $\beta$ gal expression on 293 cells. 
capable of directing the production of infectious LV particles from a variety of cell types, and that the LV yield is dependent upon the MOI and the target cell type.

To determine how long cells can produce LV after being infected with the HL first-stage HDAdV vector, a time-course experiment was performed. After infection of Hep3B cells with the HL first-stage HDAdV vector at an MOI of 10, the culture medium was harvested and replaced with fresh medium every day. The LV titers of the conditioned media harvested daily were measured on secondary target cells and were found to increase, reaching a peak level by day 3 postHDAdV infection $\left(1.3 \times 10^{4} \mathrm{TU} / \mathrm{ml}\right.$; Fig. $\left.2 \mathrm{C}\right)$. Thereafter, HL- infected human cells continued to sustain LV production for several days (postinfection day 6 titer $=2.0 \times 10^{3} \mathrm{TU} / \mathrm{ml}$ ).

\section{In vitro persistence of second-stage LV-transduced cells following $H L$ first-stage HDAdV infection}

The spread of lentivirus in long-term cultures of $\mathrm{HL}$ infected cells was examined by maintaining infected Hep3B in culture (Fig. 3A). As expected, GFP expression from the adenovirus backbone significantly decreased over time because of ongoing cell division-mediated dilution of HDAdV episomes in the culture. The percentage of GFP-positive cells
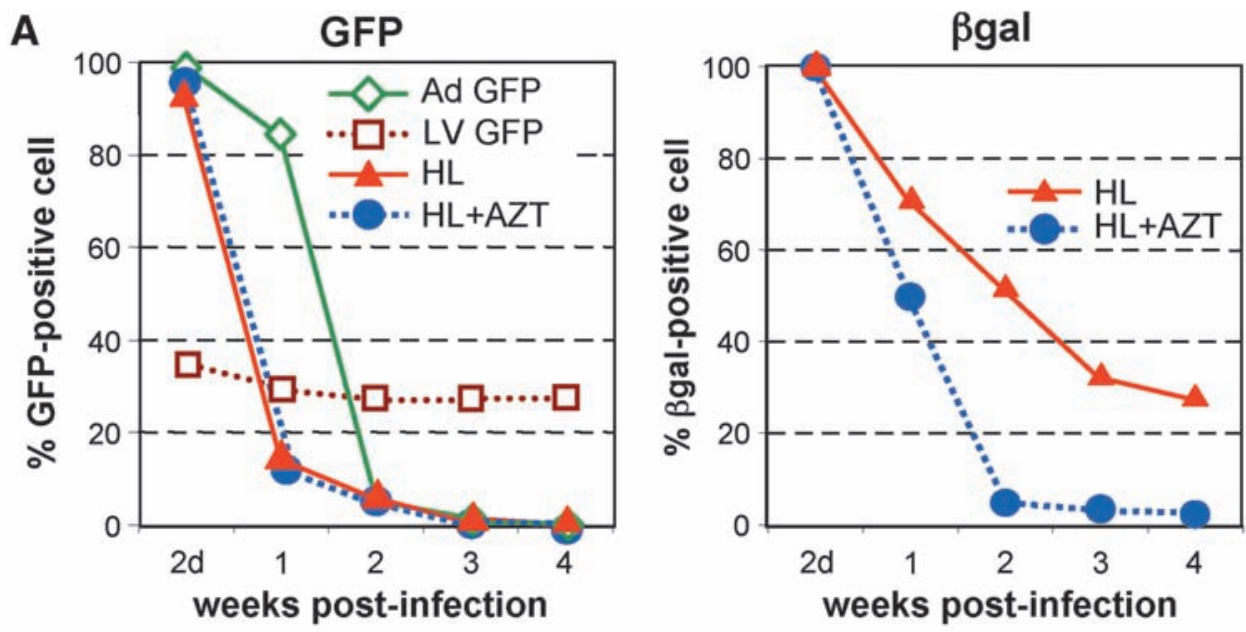

B

GFP

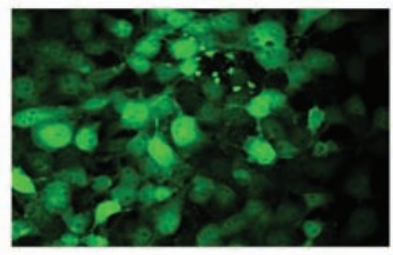

$1 w$

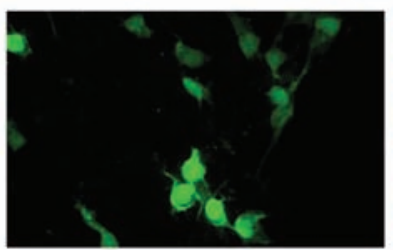

$4 w$

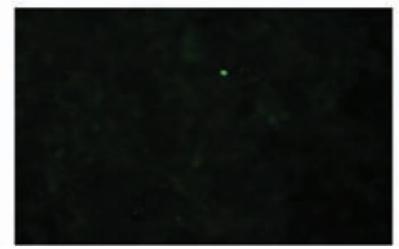

$\beta$ gal
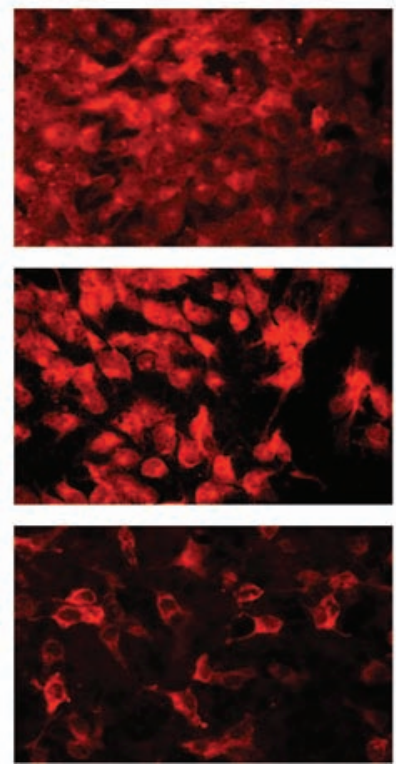

Overlay
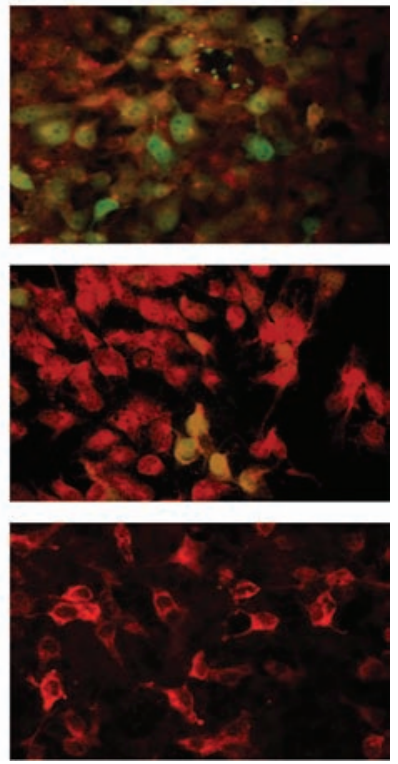

FIG. 3. Spread of LV-transduced cells and persistent gene expression following HL vector infection. (A) Transduction efficiencies of HL hybrid vector-infected cells. Hep3B cells $\left(2 \times 10^{5}\right)$ infected with the HL vector at an MOI of 10 were incubated overnight, and the cells were split the following day and cultivated in the presence (blue circle) or absence (red triangle) of AZT on a 10-cm dish. The control samples infected with an LV GFP (brown square) or an Ad GFP (green diamond) are also shown. The cells were passaged at a ratio of 1:20 every week, and expressions of GFP and $\beta$ gal were examined. Data are representative of three independent experiments, all yielding similar results. (B) Persistent gene expression achieved via HL hybrid vector system in transformed human hepatocytes in vitro. Hep3B cells were infected with HL vector at an MOI of 10. The cells were passaged at a ratio of 1:20 every week. Expressions of GFP and $\beta$ gal were analyzed by immunofluorescence staining using anti-GFP and anti- $\beta$ gal antibody at the indicated time points after HL infection. 
quickly decreased from $>90 \%$ to $<2 \%$ within 2 weeks postinfection in the HL-infected cells (HL and HL + AZT) as well as in cells infected with control Ad GFP. Initially, a parallel decrease in $\beta$ gal-positive cells was observed. However, $25 \%$ of the HL-infected cells (HL) remained $\beta$ gal positive at 4 weeks postinfection, whereas those in the HL-infected/ AZT-treated cells ( $\mathrm{HL}+\mathrm{AZT}$ ) were $<2 \% \beta$ gal positive within 2 weeks postinfection. Persistent $\beta$ gal expression in the HLinfected cells (HL) was also confirmed by IF staining (Fig. 3B). Southern hybridization of high-molecular-weight genomic DNA extracted from the cells at week 4 confirmed LV proviral integration and a direct correlation between $\beta$ gal expression and the copy number of the integrated $\beta$ gal transgenes (data not shown). This also demonstrates that persistent $\beta$ gal expression in the HL-infected cells is mediated by stable transduction with the HL second-stage LV vector.

\section{In vivo persistence of second-stage $L V$-transduced cells in humanized liver following intravenous administration of $H L$ first-stage HDAdV}

In vivo testing of the HL vector system requires a model that is permissive for assembly of human lentivirus. We employed a unique humanized model in which endogenous murine hepatocytes are extensively replaced with human hepatocytes. The replacement indices, calculated as the frequency of human-specific CK8/18-positive regions relative to that of the entire examined area in the mouse liver (Tateno et al., 2004), ranged from $63.7 \%$ to $86.6 \%$ (Fig. 4A). This model was found to be efficiently transduced by control HDAdV (HDA28E4LacZ) (Palmer and Ng, 2003) (data not shown), and so chimeric uPA/SCID mice with highly humanized livers were intravenously injected with the HL first-stage HDAdV vector.

First, GFP expression from the adenoviral backbone of the HL first-stage HDAdV in liver tissue was analyzed by flow cytometry. The results showed $7.64 \% \pm 1.33 \%$ GFP-positive cells at 4 days postinfection and $0.21 \% \pm 0.07 \%$ GFPpositive cells at 4 weeks postinfection. This reduction in GFP-positive hepatocytes was also confirmed by IF (Fig. 4B) and IHC (Fig. 4C).

On the other hand, $\beta$ gal expression persisted for at least 4 weeks postinfection as shown by IF studies (Fig. 4D) and X-gal tissue staining (Fig. 4E). Quantitation by image analysis revealed that the percentage of $\beta$ gal-positive cells increased from $16.21 \% \pm 3.70 \%$ at 4 days, to $28.40 \pm 4.92 \%$ at 4 weeks postinfection ( $p=0.0074$ ). The persistence of $\beta$ gal expression suggested that stable integration by the second-stage LV might have occurred. To demonstrate integration of secondstage LV in human hepatocyte genomic DNA in vivo, nested Alu-lentivirus PCR was performed (Nguyen et al., 2002; Serafini et al., 2004). In this assay, the first round of PCR was performed using a sense primer specific for human Alu sequences and another primer specific for the lentiviral $5^{\prime}$ noncoding region as the antisense primer (Alu-s and $5 \mathrm{NC} 2$-as, respectively; Fig. 5A). As LV vectors randomly integrate at multiple sites and repetitive $A l u$ sequences are scattered throughout the human genome, the first reaction generated products with variable sizes (Fig. 5B, PCR1). The second round of PCR, using nested primers within the viral LTR and the viral primer binding site, respectively ("LTR9-s" sense and "U5 PBS-as" antisense primers, as depicted in Fig. 5A), generated the expected 140-bp product from transduced liver tissues, but not from untransduced control liver (Fig. 5B, PCR1 + PCR2). Genomic DNA from transduced cells subjected only to second-round PCR amplification did not yield any signal, validating the inability of the nested primers alone to amplify any residual episomal LV sequences and confirming the requirement for first-round amplification with the $A l u$-lentivirus primers to detect integrated proviruses (Fig. 5B, PCR2). Although this is not a quantitative assay, taken together these results do demonstrate integration of the lentiviral sequences into the genome of human hepatocytes in vivo.

For further quantitative assessment of the percentage of cells expressing $\beta$ gal from the lentivirus vector component, Q-PCR was again performed, this time using high-molecularweight genomic DNA from each of liver tissues as the template and with primers and probe specific for the $\beta$ gal gene. The Q-PCR results demonstrated that the percentage of $\beta$ gal-positive cells was $13.8-56.6 \%$ at 4 weeks postinfection, correlating with the data obtained by Xgal staining $(28.40 \% \pm 4.92 \%)$ (Fig. $4 \mathrm{E})$. These results indicate that in situ production and spread of second-stage LV had occurred in the humanized livers of chimeric mice following systemic administration of the HL first-stage HDAdV, and taken together with the above finding that the first-stage HDAdV was undetectable at 4 weeks postinfection, it is likely that $\beta$ gal expression at a later time point is derived almost entirely from the second-stage LV.

To assess any potential vector-related hepatotoxicity, serum AST levels were measured and compared between HL vector-injected and control PBS-injected mice. It should be noted that the levels of serum liver enzymes in the uPA/SICDbased chimeric mouse model are generally high because of the ongoing hepatic expression of uPA, which mediates progressive destruction of murine hepatocytes and thereby allows gradual engraftment of human hepatocytes. Notably, however, there was no significant difference in the serum AST levels between HL-injected mice $(272.5 \pm 154.5 \mathrm{U} / \mathrm{l})$ and PBStreated group $(453.0 \pm 79.3 \mathrm{U} / \mathrm{l})(p=0.1546)$. Consistent with these findings, liver histology showed no significant difference between PBS- and HL vector-treated livers. Taken together with the serum AST levels, this indicates that the HL vector does not cause significant liver toxicity. In addition, as noted earlier, serum levels of human albumin remained at high values $(>5 \mathrm{mg} / \mathrm{ml}$ ) throughout these experiments, and replacement indices remained at high levels, ranging from $63.7 \%$ to $86.6 \%$ (Fig. $4 \mathrm{~A}$ ), further indicating that the HL vector does not show any selective toxicity that would alter the proportion of human hepatocytes.

\section{Discussion}

The liver has a variety of characteristics that make it a significant target for gene therapy (Ferry and Heard, 1998). As the liver is the site of essential metabolic pathways, it is involved in many inborn metabolic diseases. Moreover, because of its highly vascularized architecture and position as a portal to blood circulation, the liver can serve as a secretory organ for the systemic delivery of therapeutic proteins. Because of the fenestrated structure of its endothelium, the liver parenchyma is readily accessible to large molecules such as DNA or recombinant viruses via the blood stream. AdVs accumulate 

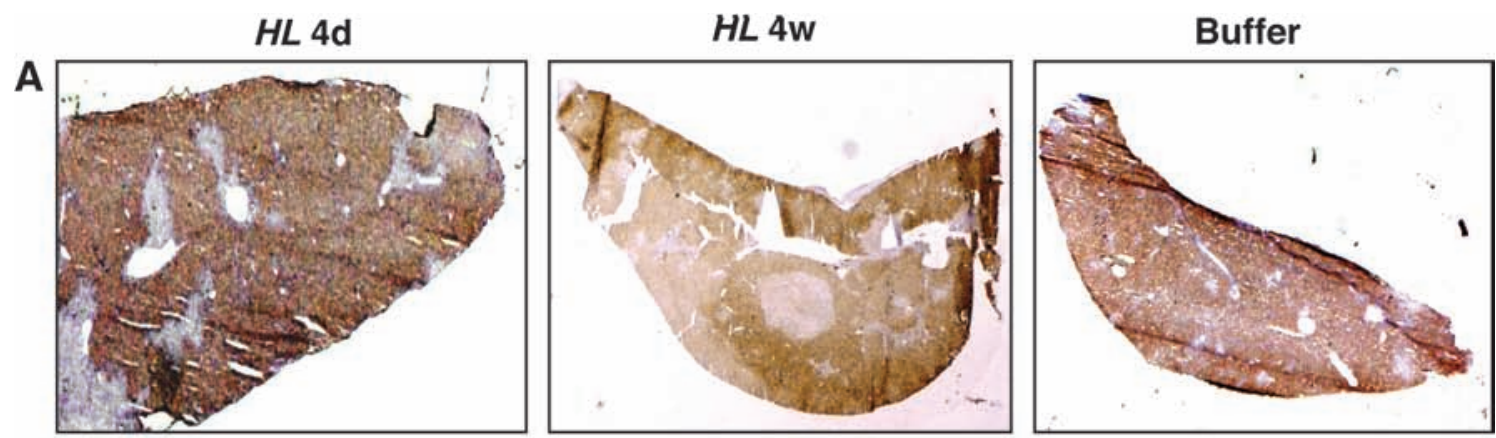

B
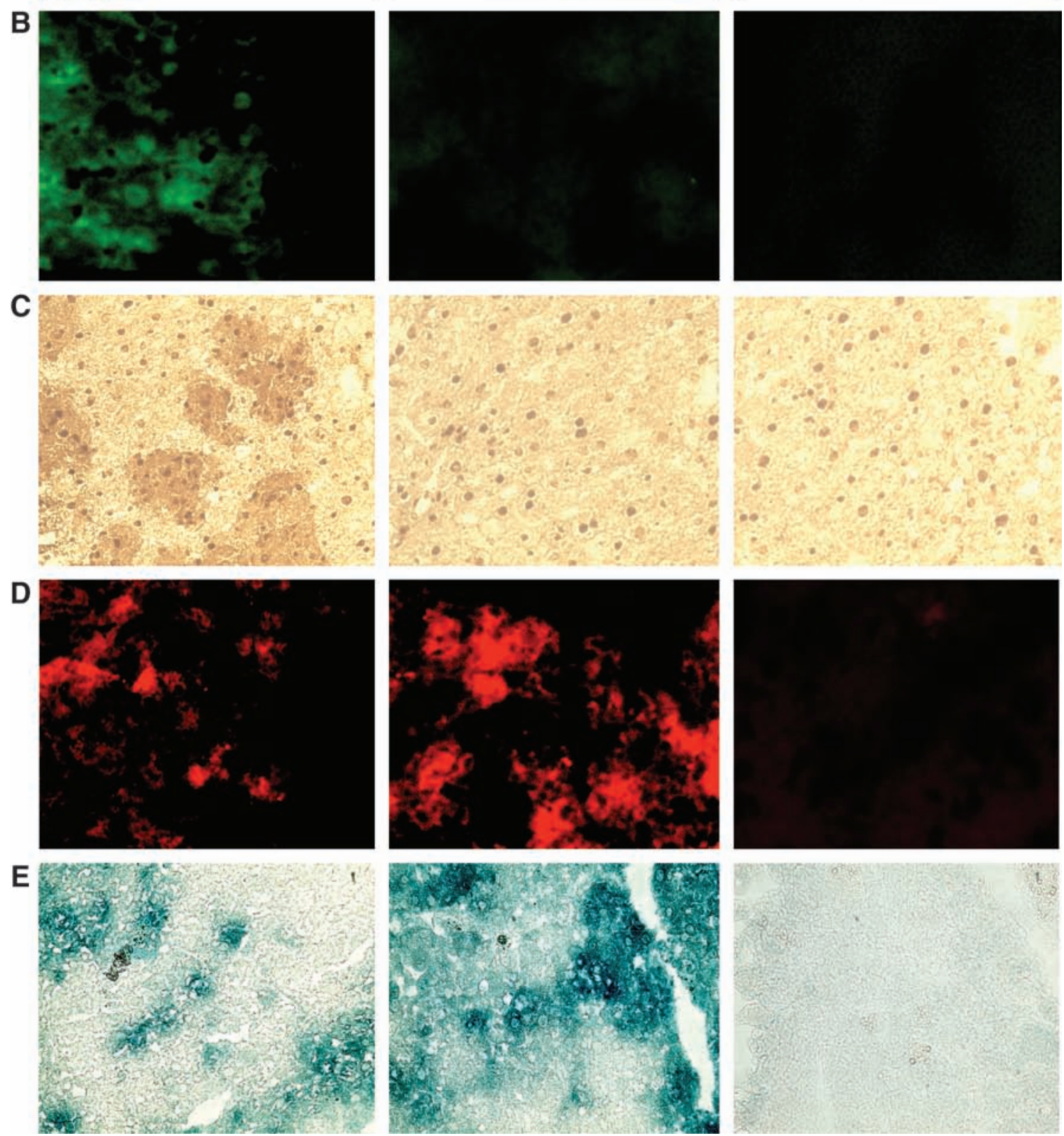

FIG. 4. In vivo transduction in humanized liver of the chimeric mice via HL hybrid vector system. The mice were injected with HL vector or phosphate-buffered saline (PBS) buffer. At indicated time points following HL infection, liver tissue was analyzed for GFP and $\beta$ gal expression as follows: (A) Human CK8/18 immunostaining to determine replacement index of the mouse liver with human hepatocytes (human hepatocytes appear brown). Original magnification: 10×. (B) Immunofluorescence stain for GFP. Original magnification: 200x. (C) Immunohistochemical stain for GFP. Original magnification: $200 \times$. (D) Immunofluorescence staining for $\beta$ gal. Original magnification: $\times 200$. (E) X-gal staining. Original magnification: $\times 100$. Representative sections of each stain are shown. 
A

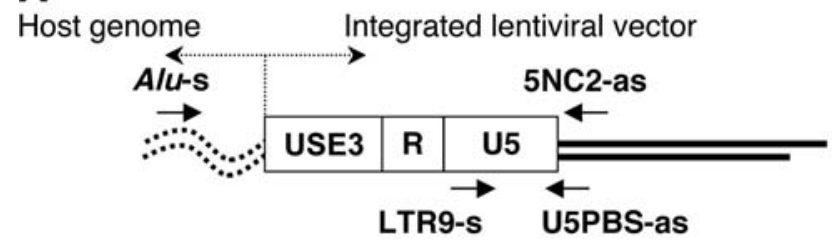

B
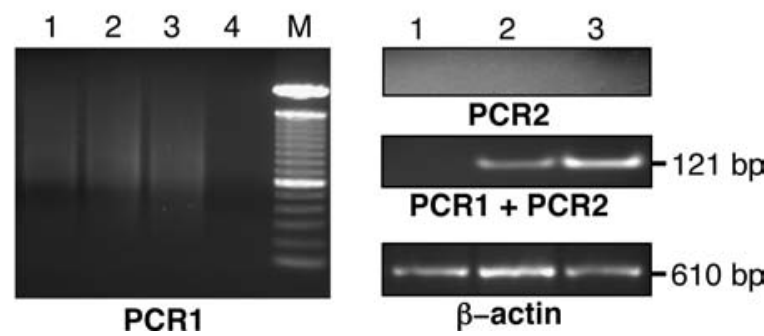

FIG. 5. Detection of integrated second-stage LV in liver tissue from chimeric mice after HL vector administration. (A) Design of nested polymerase chain reaction (PCR) analysis to amplify sequences spanning adjacent $A l u$ repeats in the human genome (Alu-s and 5NC2-as) and the integrated lentiviral LTR (LTR9-s and U5PBS-as) (Nguyen et al., 2002; Serafini et al., 2004). (B) Result of nested PCR analysis: PCR1 and PCR2 correspond to the first and second rounds of nested PCR, respectively. M, 1-kb molecular mass size ladder (Invitrogen); lane 1, PBS-treated; lane 2, HL-infected, 4 days postinfection; lane 3, HL-infected, 4 weeks postinfection; lane 4 , no DNA template. The 121-bp final amplification product is indicated. A 500-bp region of the human $\beta$-actin gene was amplified from the same samples as an internal control.

in the liver when injected intravenously (Kass-Eisler et al., 1994; Huard et al., 1995; Kubo et al., 1997) and can achieve efficient hepatic gene delivery in vivo ( $\mathrm{Li}$ et al., 1993). The newer HDAdV system evades immune responses against transduced cells, thereby achieving long-term expression in the liver (Kim et al., 2001; Oka et al., 2001). However, HDAdV vectors still cannot overcome the limited duration of expression due to dilution of viral DNA as cells start to divide, a situation exacerbated if corrected hepatocytes have a selective growth advantage (Overturf et al., 1996; De Vree et al., 2000). Thus, the use of integrating vectors such as oncoretroviruses and lentiviruses has also been pursued.

However, hepatocytes are usually arrested in the $G_{0}$ phase of the cell cycle (Ferry and Heard, 1998), and the in vivo transduction efficiency of oncoretrovirus vectors is extremely low unless cell division is stimulated by growth factors or partial hepatectomy (Bosch et al., 1996; Patijn et al., 1998). In fact, the transduction efficiency of oncoretroviral vectors in the present uPA/SCID humanized liver model is only about 5\% (Emoto et al., 2005). Even though cellular mitosis is not absolutely required for lentiviral transduction, it has been reported that hepatocytes may be refractory even to lentiviral transduction unless they progress into the cell cycle (Park et al., 2000), and certainly lentiviruses are incapable of efficiently transducing cells in $\mathrm{G}_{0}$ phase, presumably because of lack of sufficient free nucleotide pools to support reverse transcription (Naldini et al., 1996; Korin and Zack, 1998). As AdVs can readily infect nondividing cells (Benihoud et al., 1999), it is quite advantageous to employ HDAdV as an efficient firststage delivery vehicle for initial transient transduction of hepatocytes in vivo.

As the UPA/SCID chimeric mice are immunodeficient (Tateno et al., 2004) and our hybrid vector is based on the HDAdV system which itself exhibits low immunogenicity (Kim et al., 2001; Oka et al., 2001), it might be anticipated that the HDAdV vector backbone would persist for an extended period of time in the engrafted human hepatocytes. Instead, expression of GFP in the humanized livers decreased significantly within 4 weeks after HL infection. It is possible that the toxic effects of HL-derived protein products (HIVassociated proteins and marker gene products) in the transduced cells might contribute to the activation of cell cycling in the liver; however, serum AST levels and liver histology of vector-injected animals were not significantly different from those of controls. In any case, loss of the HL-adenoviral episome would actually be advantageous to shutdown further production of the second-stage LV. To increase safety, a regulatable expression system could also be introduced into the hybrid vector to regulate LV production as reported previously (Kubo and Mitani, 2003).

Second-stage LV production in situ following HL vectormediated hepatic gene transfer was assessed in vivo using chimeric mice in which the replacement indices indicated that the livers were almost completely repopulated with human hepatocytes. These chimeric mice have previously been shown to be a useful model for assessing the functions and pharmacological responses of human hepatocytes (Tateno et al., 2004), but had never been previously employed in the evaluation of gene transfer efficiency with viral vectors.

In this humanized liver model, we observed persistent $\beta$ gal expression associated with detection of integrated lentivirus sequences, despite a progressive decrease in GFP expression, suggesting that successful in situ production of LV had been achieved in HL-infected human hepatocytes. As noted earlier, stimulation of hepatocellular cycling after first-stage HDAdV infection might have accelerated the loss of adenoviral episomes, but may also have helped to enhance second-stage LV-mediated transduction of adjacent cells. As endogenous expression of the amphotropic envelope generally results in sequestration of the viral receptor and resistance to superinfection, it seems unlikely that cells initially transduced by the first-stage HDAdV would be reinfected with the second-stage LV. Genomic integration of the second-stage lentivirus vector was confirmed by PCR using human Alu and HIV LTRspecific primers. These data provide proof-of-principle for the use of the HL hybrid vector system to transduce liver parenchyma in vivo and for the use of the uPA/SCID mice as a model for gene delivery to human hepatocytes.

\section{Acknowledgments}

The authors thank Pedro Lowenstein for providing the FLP recombinase-based HDAdV helper system; Luigi Naldini and Didier Trono for the lentiviral packaging constructs; Stefan Kochanek for the STK plasmid; Paula Cannon for the minimal lentiviral vector; Chimoto Ohnishi for flow cytometric analysis; Maria Barcova, Celina Ngiam, and Ruth Margalit for their help during the preliminary phase of this work; and Karin Gaensler for helpful discussion. This work was supported by an NIH grant R01 CA93709 (to N.K.). 


\section{Disclosure Statement}

No competing financial interests exist.

\section{References}

Benihoud, K., Yeh, P., and Perricaudet, M. (1999). Adenovirus vectors for gene delivery. Curr. Opin. Biotechnol. 10, 440-447.

Bieniasz, P.D., and Cullen, B.R. (2000). Multiple blocks to human immunodeficiency virus type 1 replication in rodent cells. J. Virol. 74, 9868-9877.

Bosch, A., McCray, P.B., Jr., Chang, S.M., Ulich, T.R., Simonet, W.S., Jolly, D.J., and Davidson, B.L. (1996). Proliferation induced by keratinocyte growth factor enhances in vivo retroviral-mediated gene transfer to mouse hepatocytes. J. Clin. Invest. 98, 2683-2687.

Caplen, N.J., Higginbotham, J.N., Scheel, J.R., Vahanian, N., Yoshida, Y., Hamada, H., Blaese, R.M., and Ramsey, W.J. (1999). Adeno-retroviral chimeric viruses as in vivo transducing agents. Gene Ther. 6, 454-459.

Chen, M., Kasahara, N., Keene, D.R., Chan, L., Hoeffler, W.K., Finlay, D., Barcova, M., Cannon, P.M., Mazurek, C., and Woodley, D.T. (2002). Restoration of type VII collagen expression and function in dystrophic epidermolysis bullosa. Nat. Genet. 32, 670-675.

Dandri, M., Burda, M.R., Torok, E., Pollok, J.M., Iwanska, A., Sommer, G., Rogiers, X., Rogler, C.E., Gupta, S., Will, H., Greten, H., and Petersen, J. (2001). Repopulation of mouse liver with human hepatocytes and in vivo infection with hepatitis B virus. Hepatology 33, 981-988.

De Vree, J.M., Ottenhoff, R., Bosma, P.J., Smith, A.J., Aten, J., and Oude Elferink, R.P. (2000). Correction of liver disease by hepatocyte transplantation in a mouse model of progressive familial intrahepatic cholestasis. Gastroenterology 119, 17201730.

Dorigo, O., Gil, J.S., Gallaher, S.D., Tan, B.T., Castro, M.G., Lowenstein, P.R., Calos, M.P., and Berk, A.J. (2004). Development of a novel helper-dependent adenovirus-Epstein-Barr virus hybrid system for the stable transformation of mammalian cells. J. Virol. 78, 6556-6566.

DuBridge, R.B., Tang, P., Hsia, H.C., Leong, P.M., Miller, J.H., and Calos, M.P. (1987). Analysis of mutation in human cells by using an Epstein-Barr virus shuttle system. Mol. Cell. Biol. 7, 379-387.

Emoto, C., Tateno, C., Hino, H., Amano, H., Imaoka, Y., Asahina, K., Asahara, T., and Yoshizato, K. (2005). Efficient in vivo xenogeneic retroviral vector-mediated gene transduction into human hepatocytes. Hum. Gene Ther. 16, 1168-1174.

Feng, M., Jackson, W.H., Jr., Goldman, C.K., Rancourt, C., Wang, M., Dusing, S.K., Siegal, G., and Curiel, D.T. (1997). Stable in vivo gene transduction via a novel adenoviral/retroviral chimeric vector [see comments]. Nat. Biotechnol. 15, 866-870.

Ferry, N., and Heard, J.M. (1998). Liver-directed gene transfer vectors. Hum. Gene Ther. 9, 1975-1981.

Graham, F.L., Smiley, J., Russell, W.C., and Nairn, R. (1977). Characteristics of a human cell line transformed by DNA from human adenovirus type 5. J. Gen. Virol. 36, 59-74.

Harui, A., Suzuki, S., Kochanek, S., and Mitani, K. (1999). Frequency and stability of chromosomal integration of adenovirus vectors. J. Virol. 73, 6141-6146.

Hofmann, W., Schubert, D., Labonte, J., Munson, L., Gibson, S., Scammell, J., Ferrigno, P., and Sodroski, J. (1999). Speciesspecific, postentry barriers to primate immunodeficiency virus infection. J. Virol. 73, 10020-10028.
Huard, J., Lochmuller, H., Acsadi, G., Jani, A., Massie, B., and Karpati, G. (1995). The route of administration is a major determinant of the transduction efficiency of rat tissues by adenoviral recombinants. Gene Ther. 2, 107-115.

Kass-Eisler, A., Falck-Pedersen, E., Elfenbein, D.H., Alvira, M., Buttrick, P.M., and Leinwand, L.A. (1994). The impact of developmental stage, route of administration and the immune system on adenovirus-mediated gene transfer. Gene Ther. 1, 395-402.

Katoh, M., Matsui, T., Nakajima, M., Tateno, C., Kataoka, M., Soeno, Y., Horie, T., Iwasaki, K., Yoshizato, K., and Yokoi, T. (2004). Expression of human cytochromes P450 in chimeric mice with humanized liver. Drug Metab. Dispos. 32, 14021410.

Kim, I.H., Jozkowicz, A., Piedra, P.A., Oka, K., and Chan, L. (2001). Lifetime correction of genetic deficiency in mice with a single injection of helper-dependent adenoviral vector. Proc. Natl. Acad. Sci. U.S.A. 98, 13282-13287.

Kochanek, S. (1999). High-capacity adenoviral vectors for gene transfer and somatic gene therapy. Hum. Gene Ther. 10, 24512459.

Korin, Y.D., and Zack, J.A. (1998). Progression to the G1b phase of the cell cycle is required for completion of human immunodeficiency virus type 1 reverse transcription in $\mathrm{T}$ cells. J. Virol. 72, 3161-3168.

Kubo, S., Kiwaki, K., Awata, H., Katoh, H., Kanegae, Y., Saito, I., Yamamoto, T., Miyazaki, J., Matsuda, I., and Endo, F. (1997). In vivo correction with recombinant adenovirus of 4-hydroxyphenylpyruvic acid dioxygenase deficiencies in strain III mice. Hum. Gene Ther. 8, 65-71.

Kubo, S., and Mitani, K. (2003). A new hybrid system capable of efficient lentiviral vector production and stable gene transfer mediated by a single helper-dependent adenoviral vector. J. Virol. 77, 2964-2971.

Leblois, H., Roche, C., Di Falco, N., Orsini, C., Yeh, P., and Perricaudet, M. (2000). Stable transduction of actively dividing cells via a novel adenoviral/episomal vector. Mol. Ther. 1, 314-322.

Li, Q., Kay, M.A., Finegold, M., Stratford-Perricaudet, L.D., and Woo, S.L. (1993). Assessment of recombinant adenoviral vectors for hepatic gene therapy. Hum. Gene Ther. 4, 403-409.

Lieber, A., He, C.Y., Meuse, L., Schowalter, D., Kirillova, I., Winther, B., and Kay, M.A. (1997). The role of Kupffer cell activation and viral gene expression in early liver toxicity after infusion of recombinant adenovirus vectors. J. Virol. 71, 87988807.

Lieber, A., Steinwaerder, D.S., Carlson, C.A., and Kay, M.A. (1999). Integrating adenovirus-adeno-associated virus hybrid vectors devoid of all viral genes. J. Virol. 73, 9314-9324.

Mariani, R., Rutter, G., Harris, M.E., Hope, T.J., Krausslich, H.G., and Landau, N.R. (2000). A block to human immunodeficiency virus type 1 assembly in murine cells. J. Virol. 74, 38593870 .

Mercer, D.F., Schiller, D.E., Elliott, J.F., Douglas, D.N., Hao, C., Rinfret, A., Addison, W.R., Fischer, K.P., Churchill, T.A., Lakey, J.R., Tyrrell, D.L., and Kneteman, N.M. (2001). Hepatitis $C$ virus replication in mice with chimeric human livers. Nat. Med. 7, 927-933.

Naldini, L., Blomer, U., Gallay, P., Ory, D., Mulligan, R., Gage, F.H., Verma, I.M., and Trono, D. (1996). In vivo gene delivery and stable transduction of nondividing cells by a lentiviral vector. Science 272, 263-267.

Nguyen, T.H., Oberholzer, J., Birraux, J., Majno, P., Morel, P., and Trono, D. (2002). Highly efficient lentiviral vector-mediated 
transduction of nondividing, fully reimplantable primary hepatocytes. Mol. Ther. 6, 199-209.

Oka, K., Pastore, L., Kim, I.H., Merched, A., Nomura, S., Lee, H.J., Merched-Sauvage, M., Arden-Riley, C., Lee, B., Finegold, M., Beaudet, A., and Chan, L. (2001). Long-term stable correction of low-density lipoprotein receptor-deficient mice with a helper-dependent adenoviral vector expressing the very low-density lipoprotein receptor. Circulation 103, 1274-1281.

Ory, D.S., Neugeboren, B.A., and Mulligan, R.C. (1996). A stable human-derived packaging cell line for production of high titer retrovirus/vesicular stomatitis virus G pseudotypes. Proc. Natl. Acad. Sci. U.S.A. 93, 11400-11406.

Overturf, K., Al-Dhalimy, M., Tanguay, R., Brantly, M., Ou, C.N., Finegold, M., and Grompe, M. (1996). Hepatocytes corrected by gene therapy are selected in vivo in a murine model of hereditary tyrosinaemia type I. Nat. Genet. 12, 266-273.

Palmer, D., and $\mathrm{Ng}$, P. (2003). Improved system for helperdependent adenoviral vector production. Mol. Ther. 8, 846-852.

Park, F., Ohashi, K., Chiu, W., Naldini, L., and Kay, M.A. (2000). Efficient lentiviral transduction of liver requires cell cycling in vivo. Nat. Genet. 24, 49-52.

Parks, R.J., Chen, L., Anton, M., Sankar, U., Rudnicki, M.A., and Graham, F.L. (1996). A helper-dependent adenovirus vector system: Removal of helper virus by Cre-mediated excision of the viral packaging signal. Proc. Natl. Acad. Sci. U.S.A. 93, 13565-13570.

Patijn, G.A., Lieber, A., Schowalter, D.B., Schwall, R., and Kay, M.A. (1998). Hepatocyte growth factor induces hepatocyte proliferation in vivo and allows for efficient retroviralmediated gene transfer in mice. Hepatology 28, 707-716.

Picard-Maureau, M., Kreppel, F., Lindemann, D., Juretzek, T., Herchenroder, O., Rethwilm, A., Kochanek, S., and Heinkelein, M. (2004). Foamy virus-adenovirus hybrid vectors. Gene Ther. 11, 722-728.

Recchia, A., Parks, R.J., Lamartina, S., Toniatti, C., Pieroni, L., Palombo, F., Ciliberto, G., Graham, F.L., Cortese, R., La Monica, N., and Colloca, S. (1999). Site-specific integration mediated by a hybrid adenovirus/adeno-associated virus vector. Proc. Natl. Acad. Sci. U.S.A. 96, 2615-2620.

Robbins, P.B., Skelton, D.C., Yu, X.J., Halene, S., Leonard, E.H., and Kohn, D.B. (1998). Consistent, persistent expression from modified retroviral vectors in murine hematopoietic stem cells. Proc. Natl. Acad. Sci. U.S.A. 95, 10182-10187.

Schiedner, G., Morral, N., Parks, R.J., Wu, Y., Koopmans, S.C., Langston, C., Graham, F.L., Beaudet, A.L., and Kochanek, S. (1998). Genomic DNA transfer with a high-capacity adenovirus vector results in improved in vivo gene expression and decreased toxicity. Nat. Genet. 18, 180-183.

Sena-Esteves, M., Saeki, Y., Fraefel, C., and Breakefield, X.O. (2000). HSV-1 amplicon vectors-simplicity and versatility. Mol. Ther. 2, 9-15.
Serafini, M., Naldini, L., and Introna, M. (2004). Molecular evidence of inefficient transduction of proliferating human B lymphocytes by VSV-pseudotyped HIV-1-derived lentivectors. Virology 325, 413-424.

Soifer, H., Higo, C., Kazazian, H.H., Jr., Moran, J.V., Mitani, K., and Kasahara, N. (2001). Stable integration of transgenes delivered by a retrotransposon-adenovirus hybrid vector. Hum. Gene Ther. 12, 1417-1428.

Soifer, H., Higo, C., Logg, C.R., Jih, L.J., Shichinohe, T., HarboeSchmidt, E., Mitani, K., and Kasahara, N. (2002). A novel, helper-dependent, adenovirus-retrovirus hybrid vector: Stable transduction by a two-stage mechanism. Mol. Ther. 5, 599-608.

Tan, B.T., Wu, L., and Berk, A.J. (1999). An adenovirus-EpsteinBarr virus hybrid vector that stably transforms cultured cells with high efficiency. J. Virol. 73, 7582-7589.

Tateno, C., Yoshizane, Y., Saito, N., Kataoka, M., Utoh, R., Yamasaki, C., Tachibana, A., Soeno, Y., Asahina, K., Hino, H., Asahara, T., Yokoi, T., Furukawa, T., and Yoshizato, K. (2004). Near completely humanized liver in mice shows humantype metabolic responses to drugs. Am. J. Pathol. 165, 901-912.

Umana, P., Gerdes, C.A., Stone, D., Davis, J.R., Ward, D., Castro, M.G., and Lowenstein, P.R. (2001). Efficient FLPe recombinase enables scalable production of helper-dependent adenoviral vectors with negligible helper-virus contamination. Nat. Biotechnol. 19, 582-585.

Wivel, N.A., Gao, G.-P., and Wilson, J.M. (1999). Adenovirus vectors. In The Development of Human Gene Therapy. T. Friedmann, ed. (Cold Spring Harbor Laboratory Press, Cold Spring Harbor, NY) pp. 87-110.

Yant, S.R., Ehrhardt, A., Mikkelsen, J.G., Meuse, L., Pham, T., and Kay, M.A. (2002). Transposition from a gutless adenotransposon vector stabilizes transgene expression in vivo. Nat. Biotechnol. 20, 999-1005.

$$
\begin{array}{r}
\text { Address correspondence to: } \\
\text { Dr. Shuji Kubo } \\
\text { Laboratory of Host Defenses } \\
\text { Institute for Advanced Medical Sciences } \\
\text { Hyogo College of Medicine } \\
\text { 1-1, Mukogawa-cho, Nishinomiya } \\
\text { Hyogo 663-8501 } \\
\text { Japan } \\
\text { E-mail: s-kubo@hyo-med.ac.jp }
\end{array}
$$

Received for publication February 22, 2009; accepted after revision September 2, 2009.

Published online: December 17, 2009. 